\title{
The Use of Asynchronous Forum to Enhance Reading Comprehension of Distance Learners
}

\author{
Maslawati Mohamad ${ }^{1}$, Supyan Hussin ${ }^{2}$, Zaini Amir ${ }^{2}$, Azizah Ya'acob ${ }^{1}$, Saadiah Kummin ${ }^{1} \&$ Azizah Zahidi $^{1}$ \\ ${ }^{1}$ Centre of General Studies, National University of Malaysia, Bangi, Selangor, Malaysia \\ ${ }^{2}$ School of Language Studies and Linguistics, Faculty of Social Sciences and Humanities, National University of \\ Malaysia, Bangi, Selangor, Malaysia \\ Correspondence: Maslawati Mohamad, Centre of General Studies, National University of Malaysia, Bangi, \\ Selangor, Malaysia. Tel: 60-13-327-0680. E-mail: maslawatimohamad@yahoo.com
}

Received: August 9, 2012 Accepted: September 10, 2012 Online Published: November 30, 2012

doi:10.5539/ass.v8n15p124 URL: http://dx.doi.org/10.5539/ass.v8n15p124

\begin{abstract}
The Internet is widely available in Malaysia and due to improved bandwidth, and students now spend considerable time reading online materials (hypermedia documents) in order to complete their assignments. This is especially the case for distance learners who have little opportunity to attend face-to-face tutorials and rely instead on course materials that are uploaded to the institution's website. This case study explored the extent to which an asynchronous forum enhances the reading comprehension of distance learners specific to Life Sciences hypermedia documents. As part of their assignments, students discussed two questions via the online forum which were designed with the intent of assisting them in developing fuller comprehension of two course units. Semi-structured interviews, observations and document analysis (online forum discussion threads) were employed to assess effects. It was found that feedback through discussion via an asynchronous forum enhanced levels of comprehension for the students involved. It was also found that an asynchronous forum provides ample time for students to read extensively and subsequently discuss subject materials when they are ready to do so, and in a convenient manner. It was also found that students obtained and shared information from a myriad of sources which promoted intensive and extensive reading. It is believed that this study provides insights that will assist course designers as well as teachers in increasing student reading comprehension through asynchronous forum, in terms of the needs, difficulties and requirements of distance learners.
\end{abstract}

Keywords: asynchronous forum, reading online, reading comprehension, distance learners

\section{Introduction}

Malay is the national language of Malaysia and functions as a medium of communication and instruction throughout the country. The English language is only taught as a subject in primary and secondary education. This educational policy has resulted in most Malaysians being able to read and communicate in English but only a small percentage of the population is highly proficient in the language, particularly at the level of academic. The educational system changes when students enrol in most higher education institutions in the country, however. At the tertiary level students are expected to comprehend reference texts, which are typically written in English, in order to make academic presentations, complete assignments and answer evaluation questions.

Given this, a preparatory reading course entitled "English for Life Sciences (ELS)" was made compulsory for first year Bachelor students registered in the Faculty of Allied Sciences, National University of Malaysia (UKM). This course is designed to confer reading strategies, and improve linguistic skills and student vocabulary in the Life Sciences with the objective of improved understanding of the field's academic texts. This course has succeeded in achieving its objectives when offered to on-campus students. Challenges have arisen, however, when it is offered to distance learners. Previously, course faculty would travel to each state in Malaysia to deliver face-to-face tutorials and lectures to distance learners. These students are typically adult learners serving in municipalities, hospitals and health institutions throughout the country. While online learning is well established in developed countries, it is a relatively new phenomenon in Malaysia. Recently, however, Malaysia has initiated a lifelong learning educational policy (Zaini, 2008) in which online learning plays a key role. Given this, online education and distance education have increased significantly in the country's public universities given the logistical advantages on offer (time, cost and inconvenience of travel). 
A significant challenge of online learning is the sense of isolation students experience as they seek to overcome learning difficulties individually or with little assistance from classmates or faculty (Rugayah et al., 2010). In order to encourage collaborative work among distance learners, and to develop a sense of community (Dawson 2006), ELS course designers integrated an online forum in the course: a medium allowing students to share their comprehension of reading materials and mediate reading or learning difficulties. While research advocates the use of asynchronous forum for collaborative learning activities (Wang \& Newlin, 2001; Curtin, 2002), the effectiveness of this medium in enhancing reading comprehension is still in question within the Malaysian context, and specifically in terms of ELS distance learners.

This study was undertaken to explore to what extent an asynchronous forum enhanced the reading comprehension of distance learners specific to Life Sciences hypermedia documents. Studies of this nature are limited in the Malaysian context. An associated objective of the study was to identify needs, difficulties and requirements of asynchronous forum in terms of learning effectiveness. As Ramesh and Sanjaya (2007) indicate that awareness of this medium and its characteristics encourage adoption among faculty and acquisition of the associated pedagogical requirements (e.g., sufficient guidance, frequent encouragement, and feedback to forum participants).

\section{Literature Review}

\subsection{Computer-mediated Communication and Constructivism}

Our interest in developing online forum for distance learners in the ELS course was aroused by Barnes's (2003) work on Computer-mediated communication: Human-to-human communication across the Internet. Barnes believes that an online forum is important for distance learners in terms of a sense of physical presence students may develop despite being physically isolated from one another. This is supported by Ranjit and Mohamed Amin (2010) in their study which investigated the roles of Malaysian adult learners in Asynchronous Computer-Mediated Communication found that learners experienced different roles such as initiators-wrappers, task orienters, social discourse networkers, e-collaborators, and e-mentors in their quest to seek knowledge and improve their learning skills. Similarly, students need to develop the motivation to read (Nuttall, 2005) and as time progresses these students are involved in discussions with other classmates such that community participation instils a motivation to read more extensively (Yahya, 2008).

This viewpoint is consistent with Vygotsky (1978), a key proponent of constructivism, who believes that collaborative learning results in better comprehension of an issue. Another theme in Vygotsky's writing is that we change ourselves in the varied context of culture and history (Cole et al. 1978). People relate their knowledge and understanding of new content to their culture and history. By sharing their ideographic knowledge and culture, the community develops a more informed group of readers - that is, individuals complement one another's ideographic knowledge as they conduct community-based academic discussions. For example, when discussing issues on schizophrenia those individuals who work in a mental disorder ward would have better knowledge and experience than those who do not. They, therefore, are able to correct and inform their classmates and thus, engage in peer revision. Students in such situations find that they not only have to regulate themselves, but are also regulated by, and regulate, others. According to Hooper and Hannafin (1991) and Amelia et al. (2009) learners should employ collaborative and cooperative learning in order to facilitate constructivist learning. Learners should be able to work with other learners to develop the real-life learning experience of working in a group. This enables them to develop meta-cognitive skills as they benefit from learn from one another in the community of practicioners via online

\subsection{Schemata}

Students' schemata or world background knowledge, including their existing knowledge, will be triggered and activated when students come across certain words or ideas in their reading. In extensive reading, , they may obtain knowledge on both the content and linguistic levels. In fact, when reading an article on a certain issue and integrating new knowledge, the readers' schema specific to that issue is normally enriched (Keith 2001). The readers are then able to utilize this new schema to better understand another article which is about the same issue (Bernard 1991). They may also apply the reading strategies employed when incorporating material from the previous article in order to read other articles on similar issues (Langan, 2002). Langan finds that the result of extensive reading on the same issue is that readers become more familiar with the content, linguistic aspects (i.e., terminologies, interlocking definitions, technical taxonomies, lexical density, language features) and reading strategies. In Malaysian setting, many students, who are linguistically proficient, may not be able to handle academic reading schema competently, and still require the assistance of teachers or lecturers (Jariah Mohd Jan \& Rosli Talif, 2005; Muhammad Kamarul Kabilan et al. 2010). These students depend very much on the 
instructors, and still expect to be spoon fed in their academic pursuit. Even when the students are taught to apply certain strategies to help them understand the text, it was discovered that they were unsure whether they have identified, underlined or highlighted the right key words or main points of the text (Noorizah Mohd. Noor, 2006).

\subsection{Motivation}

As course designers, we have experienced the need for substantial marking of participation in an asynchronous forum. This is due to the fact that adult learners are busy people with various responsibilities, having little interest in devoting time to non-rewarding activities. This is also in line with Behaviourist Theory (Bigge \& Shermis, 2004) where learning is approached from the perspective of reinforcement mechanisms - in this case, punishments or rewards allocated by faculty. Reward in the present context refers to the percentage of marks and peer responses obtained by a participant. In a series of studies on online forum in the classroom, Supyan (2008) found that students would actively participate in online discussion when participation was graded and moderated by the class instructor. In the ELS course language, accuracy was not the criterion for evaluation since the objective was to promote interaction and boost reading comprehension, rather than inhibit students who were working in a second language.

\subsection{Online Forum}

What is an online forum? There are many views on the matter but Patrikis (1995) views online communication as a medium of free interaction between communicators. Other scholars, including Moran and Hawisher (1998), point out that online communication is an amalgam of written and spoken language. When participating in online forum students take control of their own learning since they are free to change the topic or direction of their discussion as long as they remain within the scope of the posted questions. Dawson (2006) adds that online forum which promote significant learner-learner and learner-content interactions tend to develop a stronger sense of community, which generally leads to enhanced learning outcomes. Supyan and Azhar (2008: 108) also consider the function of online forum for classroom purposes, and in their view the online forum provides a platform for language instructors to extend language activities outside the classroom. One aspect that designers of such course need to ponder is the choice of the most suitable platform for use outside the classroom. This study utilized 'Nicenet' since it is straightforward, less time consuming, free and fulfilled the needs of both parties - the faculty and the students.

Course designers also need to allocate a considerable amount of time marking participation to ensure active involvement in the online forum. In the ELS context the mark of each assignment was $10 \%$ and the faculty found this to be an important factor in ensuring student participation.

\section{Research Design}

\subsection{Setting}

This study took place at National University of Malaysia (UKM) where all first year undergraduate students registered in the Faculty of Life Sciences are required to enrol in English for Life Sciences. As noted above, the course is designed to deliver reading strategies, enhance reading comprehension and equip students with an enriched Life Sciences vocabulary - all critical skills for success in the Faculty.

The distance learners attended 12 hours of face-to-face tutorials over three consecutive days during the first two weeks of a 14-week semester. At the end of week 2, they returned to their respective hometowns throughout Malaysia and were expected to become independent or self-directed learners for the following 12 weeks. The only opportunity for the instructors to meet with students during this period was during final exam, scheduled over weeks 15 and 16. From weeks 3 to 14, students were instructed to read, listen, and watch hypermedia documents and multimedia which had been prepared as their learning materials.

The course designers designed some of the hypermedia materials and divided the materials into six units according to themes, all pertaining to the domain of Health Sciences. The hypermedia documents consisted of texts from various sources, reading activities, linguistic input, video clips, PowerPoint slides, and suggested websites and film which were uploaded onto the UKM website. Students were expected to study and comprehend these materials in order to make academic presentations, complete their assignments, and answer evaluation questions.

Most distance learners studied on a part-time basis due to family and work commitments. Ages ranged from 30 to 45 years old. These students had already obtained a Diploma in Health Sciences and were currently working in hospitals, municipal councils and universities all over Malaysia. Prior to the study, students resorted to phone calls, text messages, emails, and online forum as modes of communication with one another, as well as with the 
faculty. Thus, we adopted an asynchronous forum as the primary mode of communication as it allowed students to communicate freely beyond the boundaries of space and time (Bender, 2003).

\subsection{Methodology}

This study employed a case study research methodology in order to conduct intensive study of a specific group of people. Merriam (2009) defines a case study as being aimed at gaining a comprehensive understanding of a situation and a process, rather than an outcome or product of the phenomena. Merriam also proposes that a combination of research instruments should be used in a case study in order to corroborate or triangulate data. The research tools used in this study were semi-structured interviews, observations and document analysis (online forum discussion threads). Data triangulation and the use of various sources of data helped in achieving credibility in this study (Denzin \& Lincoln 2000).

Purposive sampling was employed, as is often the case in this methodology. Purposive sampling allows the researcher, "...to discover, understand and gain insight from a sample from which the most could be learned" (Merriam 2009: 79). Patton (1990: 169) defines purposive sampling as the technique of selecting suitable respondents who, "...provide information-rich cases whose study will illuminate the questions under study." In the present study, a set of participants were chosen on the basis of characteristics they presented, which were deemed to be appropriate to the research questions (Dornyei, 2007). We arranged appointments with the participants according to their convenient time and place. All participants except INTAM preferred to be interviewed in their workplace. The interview sessions were conducted in their office rooms in the hospitals. Each interview session took between 60 to 90 minutes. Prior to the interview sessions, the interview questions were piloted to enhance the content and the degree of comprehensibility. One of the researchers acted as a monitor, collaborator, and motivator by participating in the online forum.

\subsubsection{Procedure}

At the beginning of the semester, the scope and timetable for the study were briefly explained to 20 participants by the researchers. These participants (constituting one class of students) took part in the asynchronous forum for 12 weeks. They were required to complete two assignments, both requiring that they read and discuss course materials in the form of hypermedia documents. In addition to this media, students were encouraged to visit prescribed websites as well as related websites which they thought would facilitate assignment completion. For each assignment, the students were required to submit at least five postings in the online forum.

Prior to the study, the students were given two evaluations: individual presentation and group discussion. Both evaluations were based on the two units of the syllabus. They need to read the given hypermedia documents, prescribed websites, and any other related websites to prepare for the two evaluations. Based on these evaluations, the researchers could gauge the students' proficiency level. Generally, the students were divided into two proficiency levels; intermediate and low. The students were given two assignments, corresponding to two units of the course, which they needed to complete via online forum discussion: "Schizophrenia" and "Designer Babies." One of the assignments is indicated in the list below:

\section{ONLINE FORUM $(10 \%)$}

Use the suggested websites to substantiate your opinions.

http://www.schizophrenia.com/family/sz.overview.htm

http://www.nobelprize.org/nobel prizes/economics/laureates/1994/nash-autobio.html

http://www.mentalhealth.org.uk/feedingminds/

http://www.emedicinehealth.com/schizophrenia/article_em.htm

http://www.schizophrenia.com/

http://www.mentalhealth.com/story/p52.html

Read the article "Moving Lives Forward" and discuss in your ONLINE FORUM.

All 20 students participated in the online forum discussion. Seven of these 20 students volunteered for in-depth observation and interviews. These volunteers were given the pseudonyms INTRA, INTLI, INTFARH, INTFA and INTAM, INTA, INTAD. All seven were observed when reading hypermedia documents or visiting websites in their attempts to construct sentences for their postings. Each of them was observed between five to seven times within one semester of sixteen weeks. Each observation took one hour. After observation, they were interviewed and their responses were transcribed verbatim. The online threaded discussions were also analyzed. The researchers also used pseudonyms for the contributors of the online forum. 


\subsubsection{Data Analysis}

To achieve credibility or internal validity, we endeavoured to carefully record all of the data accurately through the process of verbatim recording and transcription (Mackay \& Gass 2008). Creswell (2003) and Dornyei (2007) describe transcription as a process of transferring data from audio tapes into textual forms. We returned the transcripts to the participants after each interview for verification - a common strategy to ensure internal validity which Silverman (2000) and Merriam (2009) denote as "member checks". Participants were asked to review the researcher's interpretations for accuracy and plausibility (William, 2006; Trochim, 2006).. Creswell (2009) highlights the importance of a follow-up interview with participants to provide them the opportunity to comment on the transcriptions. We sent an email (which consists of their transcriptions) to each participant a few days prior to the following interview. They were asked to check and comment the transcriptions of the interview. The participants could change words, phrases, or even sentences during this process. The participants signed a form as a proof that member checking procedure had been conducted. With regard to online forum discussion thread, no modifications were made in the online discussion thread to maintain its originality.

The following steps taken for data analysis were reviewing the data, making sense of them, and organising them into codes, and then categorizing them into themes that cut across all of the data sources. Data from the interviews and online forum discussion threads were coded to document emerging themes. The data categorization was based on literature review. Anticipating that we might make mistakes in interpreting the themes and subthemes, or coding the data Cohen Kappa's (1960) test of agreement was used to minimize error, where a pair of raters was asked to further improve consistency or reliability by crosschecking the coding and definitions from the interview transcripts. This helped us in building a clear justification for the developed themes (Creswell, 2003).This analysis was then compared to content from the two teaching units ("Schizophrenia" and "Designer Babies") and a literature review. Data gathered from the interviews, observations, forum discussion threads were then collated to determine the benefits of the asynchronous forum in enhancing subject matter comprehension.

\section{Findings and Discussion}

How does an asynchronous forum enhance the reading comprehension of students? The results of this study point to the factors below. The forum

1) provides students ample time to read extensively and discuss among themselves at convenient times and places (the forum itself);

2) allows students to gain considerable information from a myriad of sources which promotes intensive and extensive reading;

3) expands each students' ideas and confirms mutual understanding;

4) encourages students to receive corrections and feedback from their classmates;

5) promotes students to complement each other's knowledge by providing sources of knowledge;

6) permits students to create opportunities for social bonding among the forum members;

7) allows students to work collaboratively to solve each other's problems and difficulties.

The following discussion focuses on only two of the seven points listed above: points 1 and 2 . The following episodes entail two sources which are the online forum threaded discussion and interview responses.

4.1 Provides Students Ample Time to Read Extensively and Discuss among Themselves at Convenient Times and Places (The Forum)

Respondents reported that one of the main factors enhancing their reading comprehension was that the asynchronous forum afforded them, at their convenience, the time to read intensively and extensively before they sent their entries to the plenary. INTFARH and INTA's responses indicate that they could read the hypermedia, suggested and supplemental websites at their own pace and place. This statement is reflected in their statements during the interview sessions:

“... because... mmm... we need to manage our time lah. Mmm... sometimes, it is not necessarily we're free every day. We need to adjust our own time. Generally, it allows time flexibility" (INTFARH)

and

"one advantage is no time limit lah, very flexible". (INTA) 
Being given ample time, these students could read extensively and reflect on their reading. Some students, particularly the weaker ones, required more time to read because they had to use techniques to solve their vocabulary problems before they comprehended the reading. Our observations indicate that low proficiency students made more attempts searching for word meanings from printed dictionaries, online dictionaries, and glossary hyperlinks or sought assistance from other people. Generally, low-proficiency students would encounter a greater number of unfamiliar words than high-proficiency students. Participants indicated in interviews that they normally posted their entries when they believed they had reached certain level of comprehension and confidence in their statements:

"Actually, online forum requires us to read and search for a lot of information, then only we could post our ideas. So, we need to access many websites to add lah our ideas". (INTA)

The respondents reported that they also had sufficient time to read other people's postings which proved useful in confirming their own comprehension. In essence, the asynchronous forum provided a platform of assistance for low proficiency students since they required more time to comprehend the hypermedia documents before being ready to submit entries to the plenary.

This finding confirms Simon's (2000: 73) opinion, “...the main objective of asynchronous forum is to provide opportunity to maximize an individual's learning experience by selecting his own time. Moreover, some people think best in the morning while others in the afternoon." In short, an asynchronous forum is suitable for adult learners who can ill afford becoming full-time students due to their lack of time and the constraints of traditional education. Adult learners experience such constraints in becoming full-time students due to their multiple responsibilities - namely family, career and education (refer to the episodes below, which are taken from the online forum threaded discussion). Consequently, these constraints lead to issues related to time and the need for flexibility in accomplishing their reading and participation in group discussion.

Episodes (online forum threaded discussion)

FROM: ros1801 (01/30/09 7:10 AM GMT) [Send a personal message to ros 1801]

\section{SUBJECT: treatment of schizophrenia}

Today I have little time to join the forum.

INTAM

One of the reasons I could not concentrate reading because I've a meeting at three.

FROM: WZF (01/07/09 9:32 PM GMT -06:00)

Hi everybody. How are you all doing? I'm so busy here. I think my boss take revenge of me lah.

From this finding, we can conclude that an asynchronous forum is capable of replacing face-to-face group discussions which are normally conducted as pre-reading or post-reading activity in traditional educational sessions. In other words, an asynchronous forum is an alternative discussion to face-to-face classroom interactions which are limited in distance education programs. It is thus safe to conclude that an asynchronous forum provides students adequate time to develop better comprehension in the reading materials given the facilities of convenient time and place.

\subsection{Allows Students to Gain Considerable Information from a Myriad of Sources Which Promotes Intensive and Extensive Reading}

Sharing reading discoveries and ideas allowed students to complement one another's knowledge and simultaneously improved their comprehension of the topic. The following are selected responses recorded from participants during interviews regarding the sharing of ideas. INTAD noted,

"The reason I joined online forum because I could accumulate a lot of knowledge If we have to search for all the relevant information alone, I don't think we can do that because there is too much information. When we discussed, we received myriads of opinions. Some of the information is totally unexpected. That's strength"

Additionally INTFA shared the same view when she said,

"We could share ideas with others, so in terms of ideas our knowledge gets widened".

It is safe to conclude that because students came from different departments, institutions and backgrounds they had their own unique personal and working experiences. Opinions were therefore diverse. They demonstrated 
their ability to elaborate ideas as most of them had several years of working experience in health-related disciplines and possessed a diploma in that domain. It is important to note that they were able to look at and analyze each issue from different angles. This statement is evidenced from INTFARH's response:

"So, in my opinion most of the feedback is good. They included the information that they have read."

As noted above, students were also able to accumulate their knowledge from various sources - namely summaries submitted by their classmates, lectures, websites, movies, journals, books and related experiences. Through extensive reading they gradually widened their vocabulary repertoire and familiarized themselves with how such words and terms are correctly used in context.

\subsubsection{Summaries}

The majority of students posted summaries of articles which they had read, or information they had gleaned from lectures. In order to produce a summary, students had necessarily read and comprehended the material to a degree and reflected their comprehension in the resulting summaries. As students were independent learners in this program, they needed to utilize a variety of reading strategies, including cognitive, meta-cognitive, socio-affective strategies and navigational strategies, before they could compose a good summary. While composing this summary their comprehension level also developed. The summary was then sent to the asynchronous forum and read by others, and students thus shared their knowledge. The following episode, derived from the threaded discussion, illustrates one respondent summary.

FROM: INTRA (04/10/09 9:19 PM GMT -06:00) [Send a personal message to INTRA] SUBJECT: RE: Problem of treating schizophrenia in Malaysia?

Clinical efficacy of Schizophrenia treatment:

Only effective in controlling the positive symptoms acute Schizophrenia (high dose). Difficult to get the right dose from the typical drugs and less atypical drugs are developed (costly) and can be given IV. Treatment in long and continuous period of time to avoid recurrent (important to carry out daily routine). Not affective for negative Schizophrenia symptoms. About $40 \%$ chronic patients cannot be controlled by those drugs (Clozapine treatment needs agranulocytosis monitoring). Psychotherapeutic drugs are to treat symptoms of Schizophrenia only.

It was also found that towards the end of the forum, a few of the students managed to summarize or paraphrase their classmates' opinions using their own words. The excerpts derived from the threaded discussion below reveal that these students had attempted to go through the discussion thread and show their comprehension of those entries from their summaries.

FROM: MA (03/07/09 12:57 AM GMT -06:00)

\section{SUBJECT:}

After long discussion, most of us agreed that 'designer babies' arguments can be divided to: (1) arguments for creating 'designer babies' and (2) arguments against creating 'designer babies'. Either arguments have its pro and con. As per discussed by our friends in this forum earlier on, 'designer babies' only reasonably designed if:

(1) Some couples are not able to have children because their children will have a genetic disease and die before they are born or when they are very young. Techniques used to change the genetic make-up of the embryo allow these parents to have a child.

(2) Spare part children? In a few cases where parents have had one child with a serious blood disease, they have used IVF to select embryos so that they can have a second child that can act as a future, tailor-made blood or bone marrow donor. In these cases when the child is born he or she will be healthy and can help their older brother or sister stay well.

FROM: INTLI (01/18/09 8:47 PM GMT -06:00)

\section{SUBJECT: Assalamualaikum to all}

First and foremost, I have gone through all the messages. Personally, I felt there are massive information and knowledge where it provides real descriptions of schizophrenia. It descriptively clarified about the meanings of schizophrenia, its signs 
and symptoms as well as its management.

\subsubsection{Websites}

In addition to summaries, students also gained knowledge from websites as displayed in the following episodes which are extracted from discussion threads:

FROM: Mohd Fa (01/30/09 7:49 AM GMT -06:00)

SUBJECT:

I think it would be better if I could paste the MRI or CT images of the brain here, anyway you can click to this link. Thank you. http://www.schizophrenia.com/schizpictures.html

FROM: RM (03/26/09 12:38 PM GMT -06:00)

\section{SUBJECT: Society's Perception}

"schizophrenic behaviour is sinful and mental hospitals do not provide effective treatments"- excerpt of a study on schizophrenia (Kota Kinabalu 2008). http://isp.sagepub.com/cgi/content/abstract/54/2/164

We also observed that students exchanged and provided website addresses in the asynchronous forum for the benefit of other students. Some provided detailed and in-depth information on the website, while others merely gave the website address or simplistic information. We observed that 'Nicenet' is a good option as a discussion platform as it allows students to share relevant website links with other classmates who simply click on address to access it. Once students gained access to the content, they navigated according to their own thought, reading and learning strategies to comprehend the content and develop their knowledge. This is a cyclical process as students might return back and forth between the asynchronous forum and the website, and the content of the website could be reused to enhance their understanding. When students were given the freedom to choose their own reading sequence, they felt more motivated to analyze, synthesize and evaluate what they had read. When they utilized higher thinking processes, they made more associations with their long term memory which resulted in higher-level learning. Responses in the interview sessions supported the observation that students read other websites in order to prepare for a posting. This is supported by statements from INTFA and INTFARH during the interview sessions:

“... actually, before we send any postings into the online forum we need to search for information. So we're supposed to read a lot of websites, to add our ideas"

and

“... for instance, if we want to discuss a problem, first we seek the answers from browsing the Internet before we post the answers into the online forum. Some of us also attached the website address that they have read and after that we read the websites. Therefore we could do further reading."

\subsection{Related Sources}

Apart from sharing information related to websites, students also accessed related resources including films, journals, books, and their personal experiences. As such, their participation in the asynchronous forum exposed them to a variety of information leading to holistic intellectual development. This is because each student has a distinctive mental makeup which allows him or her to understand a theme differently from others. By substantiating their points of view through these sources the discussions became more meaningful as one source complemented another in enhancing comprehension. This is supported by INTAM who explained the following in the interview:

“... online forum helps me a lot. When we discussed a lot of opinions and ideas are raised. They also attached the websites that they had read. We read the attached websites."

In addition, our observation suggests that terminology and difficult words were well explained and elaborated by students participating in the forum, enhancing mutual understanding. The cluster episodes that follow are derived from the online threaded discussion and demonstrate the level of information exchange from a myriad of sources.

Films:

FROM: RM (01/10/09 9:20 PM GMT -06:00) 
SUBJECT: Split Personality?

Schizophrenia is also well depicted in hit movies such as The Three Faces of Eve (1957), One Flew over the Cuckoo Nest, and the most recently A Beautiful Mind (2001)

Journals:

FROM: ros 1801 (03/26/09 10:54 PM GMT -06:00)

SUBJECT: new information

To underscore the profound impact of this illness, an editorial in the journal Science described schizophrenia as the worst disease affecting mankind (not excepting AIDS) for the following reasons:

Lost productivity in the United States costs an estimated $\$ 20$ billion per year.

The completed suicide rate is $10 \%$.

Total economic burden of schizophrenia in the United States was estimated at $\$ 62.7$ billion in 2002.2

Books:

FROM: WZF (04/12/09 6:51 PM GMT -06:00)

\section{SUBJECT:}

Hi. did everyone know that we dont have enough sleep can lead us to mental problems? $\mathrm{i}$ read this handy book that $\mathrm{i}$ bought it at Popular book store " A CAP GUIDE - HOW SLEEP AFFECTS YOUR BODY AND MIND" published by Consumers Association of Penang

Personal experience:

FROM: INTRA (04/10/09 8:57 PM GMT -06:00)

I stay at Kajang (nearby Bandar Baru Bangi) and I think everybody should know who is Prof. Dato' Hassan Din. I've been to his Darul Syifa (clinic) and managed to see with my own eyes how he or his helpers doing the healing method towards schizophrenia sufferers.

Work experience:

FROM: INTAM (01/05/09 6:51 PM GMT -06:00)

\section{SUBJECT:}

I'm an Occupational Therapist. I also involve in psychiatric management therapy. We manage clients starting from the ward to the community.

From my point of view, the important thing in helping schizo patients is we must have a positive perception to help them getting back their quality in life. They should be assisted to be able to adapt and cope with their surrounding especially the community.

Law:

FROM: SES (02/12/09 1:22 AM GMT -06:00)

SUBJECT: Law to ban designer babies.

The government has said 'no' to designer babies. A new law, now being drafted, will forbid parents to choose the gender of their yet to be born child. To choose a baby based on its gender, the colour of its eyes or hair will not be allowed. We are against people who want to determine the sex of the babies. This is unacceptable as it will cause serious socio-economic implications on society. Under the new law, the Health Ministry has the power to stop fertility clinics which intend to carry out the so-called assisted reproductive technology (ART) involving pre-implantation genetic diagnosis (PGD) procedure for genetic testing and selection of embryos through in-vitro fertilization. 


\subsection{Different Perspectives}

The asynchronous forum also enabled participants to analyze an issue from diverse perspectives, including cultural, personal and professional perspectives, which were of considerable depth given personal and professional experience. These made the discussion thread very colourful, beneficial and interesting. Moreover, forum discussions were able to imitate face-to-face group discussions despite response delay. These findings are in parallel with those of Dawson (2006) who found that that an online forum promotes development of a learning community consisting of diverse cultural, professional and personal backgrounds. The community also enabled students to apply their meta-cognitive and socio-affective strategies. In short, they benefitted from one another's strengths and learned from diverse sources to achieve better comprehension of a theme. Furthermore, while the students were completing a given task they added new knowledge based on existing knowledge in order to incorporate new ideas. This notion is encapsulated in INTFARH's comment during the interview session when she said,

"Yes, I think online forum is very good and a... there are so many advantages here, mmm... I share a lot of experiences with friends in the online forum. Sometimes we do not have enough information when we are alone then we can share with our friends".

The following messages illustrate some of the diversity in discussing an issue.

Cultural perspectives:

FROM: rm (03/26/09 12:38 PM GMT -06:00)

\section{SUBJECT: Society's Perception}

"Results showed that Malaysians tended to favour social-environmental explanations for schizophrenia. There were also ethnic and sex differences in these results. Specifically, Malay participants more strongly agreed that schizophrenia has a social cause, that treatment should affect changes at a societal level, that schizophrenic behavior is sinful and that mental hospitals do not provide effective treatments"

Personal perspectives:

\section{FROM: WF (01/08/09 9:50 PM GMT -06:00)}

That person is one of my family. He is my uncle. He had a career. After few years, he become a very quiet person, keep talking and mumbling to himself and quit with his job. Sometimes, he acted like a kid.

\section{Conclusion}

The current educational climate has witnessed increased use of computer technology and the Internet in language classrooms. Given economic and logistic benefits, online courses are mushrooming at the tertiary level in Malaysia. The success of an online course is also affected by the student's ability to interact well via online communication (Dawson, 2006; Rugayah, 2010). This study has shown that student discussions via an asynchronous forum enhanced reading comprehension. These findings indicate that the participants benefitted from the delayed response mode and ample time afforded for participation. Discussion threads were an open space for learners to express themselves freely. When these students were provided the time to do their readings and develop their reflections, better comprehension and contributions were produced. This finding confirms Bender's (2003) viewpoint that prior to posting any ideas, respondents are involved in a process of comprehending, examining and reflecting on what they have read in terms of reading materials and online forum contributions. Students in this study examined and reflected on their viewpoints prior to, while and after posting entries to the forum - a cyclical process. In addition, their views incorporated diverse perspectives and resources. The prolonged asynchronous forum allowed students to share information, provide and counter-check one another's comprehension, as well as confirm or correct information within a forum environment that facilitated this learning process by facilitating issues related to time and space. In essence, these features of the asynchronous forum led to better reading and comprehension of a given issue or theme. Faculty were also able to monitor student online behaviour and intervene with feedback or activities to ease difficulties, confirm understandings and to promote further discussion. Together, these multiple advantages facilitated the development of a learning community.

\section{References}

Abdullah, A., Embi, M. A., \& Din, R. (2009). Development of a collaborative learning community through computer-mediated communication. In Mohamed Amin Embi (Ed.), Computer-Mediated Communication: 
Pedagogical Implications of Malaysian Research Finding (pp.112-127). Shah Alam: Karisma Publications Sdn. Bhd.

Amir, Z. (2008). Language Learning Strategies in an Online English Writing Course: A Case Study. Ph.D Thesis. Universiti Kebangsaan Malaysia.

Barnes, S. B. (2003). Computer-mediated Communication: Human-to-Human Communication across the Internet. Boston: Pearson Education.

Bender, T. (2003). Discussion-Based Online Teaching to Enhance Student Learning. Sterling: Stylus.

Bernard, L. H. (1991). The Effective Strategies for Teaching Reading. Boston: Allyn and Bacon.

Bigge, M. L., \& Shermis, S. S. (2004). Learning Theories for Teachers (6th ed.). California: Allyn and Bacon.

Cohen, J. (1960). A Coefficient of Agreement for Nominal Scales. Educational and Psychological Measurement, 20(1), 37-47. http://dx.doi.org/10.1177/001316446002000104

Cole, M., John-Steiner, V., Scribner, S., \& Souberman, E. (Eds.). (1978). Mind in Society: The Development of Higher Psychological Processes. Cambridge: Harvard University Press.

Creswell, J. W. (2003). Research Design: Qualitative, Quantitative and Mixed Method Approaches. California: SAGE Publications.

Creswell, J. W. (2009). Educational Research: Planning, Conducting, and Evaluating Quantitative and Qualitative Research (3rd ed.). New Jersey: Pearson Publications.

Curtin, J. (2002). Web CT and Online tutorials: New Possibilities for Student Interaction. Australian Journal of Educational Technology, 18(1), 110-126. Retrieved from http://www.ascilite.org.au/ajet/ajet18/curtin.html

Dawson, S. (2006). Online Forum Discussion: Interactions as an Indicator of Student Community. Australasian Journal of Educational Technology, 22(4), 495-510. Retrieved from http://www.ascilite.org.au/ajet/ajet22/dawson.html

Denzin, N., \& Lincoln, Y. (1994). Handbook of qualitative research. Thousand Oaks CA: SAGE Publications.

Dornyei, Z. (2007). Research Methods in Applied Linguistics: Quantitative, Qualitative and Mixed Methodologies. Oxford: Oxford University Press.

Hooper, S., \& Hannafin, M. J. (1991). The Effects of Group Composition on Achievement, Interaction and Learning Efficiency during Computer-based Cooperative Instruction. Educational Technology Research Development, 39(3), 27-40. http://dx.doi.org/10.1007/BF02296436

Jan, J. M., \& Talif, R. (2005). Questioning strategies and the construction of context in classroom talk. The English Teacher, XXXIV, 76-89.

Kabilan, M. K., Seng, M. K., \& Kee, O. A. (2010). Reader-Text Transaction in Text Comprehension. Journal of Language Studies, 10(3), 127-142.

Keith, K. (2001). An Introduction to Foreign Language Learning and Teaching. Pearson Edinburgh: Education Limited.

Langan, J. (2002). Reading and Study Skills (7th ed.). Boston: McGraw Hill.

Mackay, A., \& Gass, M. S. (2008). Second Language Research (2nd ed.). New York: Routledge.

Merriam, S. B. (2009). Qualitative Research: A Guide to Design and Implementation. San Francisco: Jossey-Bass.

Moran, C., \& Hawisher, G. (1998). The Rhetoric and Languages of Electronic Mail. London: Routledge.

Noor, N. M. (2006). Reading academic text: Awareness and experiences among university ESL learners. Journal of Language Studies, 6(2), 65-78.

Nuttall, C. (2005). Teaching Reading Skills. Oxford: Macmillan Publishers.

Patrikis, P. (1995). Where is Computer Technology Taking Us? ADFL Bulletin, 26(2), 36-39.

Patton, M. Q. (1990). Qualitative Evaluation and Research Methods (2nd ed.). Newbury Park, CA: SAGE.

Ramesh, C. S., \& Sanjaya, M. (2007). Global E-Learning Practices: An Introduction. In Ramesh, C. S., \& Sanjaya (Eds.), Cases on Global E-Learning Practices: Successes and Pitfalls (pp. 1-12). United Kingdom: Ideagroup Inc. Retrieved http://www.scribd.com/doc/20071798/Cases-on-Global-E-Learning-Practices-Successes-and-Pitfalls 
Rugayah, H., Hashim, A., \& Che, Z. A. (2010). Behavioural Aspects of Adult Learners in Digital Learning. Proceedings of the $5^{\text {th }}$ Conference on eLearning.

Sidhu, R. K., \& Embi, M. A. (2010). Learner e-tivities: Exploring Malaysian learners' roles in Asynchronous Computer-Mediated Communication. European Journal of Educational Studies, 2(2), 157-174. Retrieved from http://ozelacademy.com/ejes.htm

Silverman, D. (2000). Doing Qualitative Research: A Practical Handbook. London: SAGE Publications.

Simon, M. (2000). Managing Time: Developing Effective Organization. In White K.W. \& Weight, B.H. (Eds.) The Online Teaching Guide (pp. 73-83). Boston: Allyn and Bacon.

Supyan, H., \& Azhar, J. (2008). The Prospects of Online Forum at Tertiary Level. In Norizan, A. R., \& Abd. Ghafur, A. (Eds.), Policy and Implementation of E-learning at Institutions of Higher Learning (pp. 108-122). Bangi: Universiti Kebangsaan Malaysia.

Trochim, W. M. K. (2006). The Qualitative Debate. Research Methods Knowledge Base. Retrieved from http://www.social researchmethods.net/kb/qualmeth.php

Vygotsky, L. S. (1978). Mind and society. Cambridge: Harvard University Press.

Wang, A. Y., \& Newlin, M. H. (2001). Online Lectures: Benefits for the Virtual Classroom. THE Journal, 29(1), 17-24. Retrieved from http://www.thejournal.com/articles/15513

William, M. K. T. (2006). The Qualitative Debate. Retrieved from http://www.socialresearchmethods.net/kb/qualdeb.php

Yahya, O. (2008). Proses \& Strategi: Membaca Berkesan. Serdang: Penerbit Universiti Putra Malaysia. 